\title{
SITUAÇÃO E CONTEXTO: POLÍTICAS MIGRATÓRIAS E INTERAÇÕES COM REFUGIADOS NO NORTE DE ANGOLA
}

\author{
Situation and context: migratory policies and interactions \\ with refugees in northern Angola
}

Paulo Ricardo Muller

\begin{abstract}
Resumo. Neste artigo analiso o modo como se configuram as relações de refugiados, sobretudo congoleses da República Democrática do Congo (RDC), com a sociedade local e nacional, e com organizações internacionais, em duas províncias do norte de Angola: Cabinda e Lunda Norte. A partir de evidências etnográficas coletadas em um trabalho de campo realizado nestas províncias, procuro demonstrar como as representações midiáticas e definições jurídicas acerca de refugiados são ressignificadas em função dos modos de organização e representação coletiva das comunidades de estrangeiros nas províncias e cidades fronteiriças que operam como cenário concreto destes movimentos migratórios, produzindo diferentes formas de incorporação destes sujeitos aos contextos nos quais se encontram.
\end{abstract}

Palavras-chave: refugiados, imigrantes, situação social, norte de Angola.

\begin{abstract}
In this paper I analyze the configuration of the relationship between refugees, mainly from the Democratic Republic of the Congo (DRC), and local and national society and international organizations in two northern Angolan provinces: Cabinda and Lunda Norte. Drawing from ethnographic evidence collected during a fieldwork on these locations, I seek to demonstrate how mediatic representations and legal definitions concerning refugees are reframed according to the modes of collective organization and self-representations of foreign communities in the border areas that work as scenarios for migratory movements, producing different ways of incorporating immigrants and refugees to their respective social contexts.
\end{abstract}

Keywords: refugees, immigrants, social situation, northern Angola.

\footnotetext{
1 Universidade Federal da Fronteira Sul - Campus Erechim (UFFS/Erechim). Erechim, RS, Brasil.
} 
Neste artigo analiso comparativamente algumas questões levantadas pela interlocução com grupos de refugiados congoleses (da República Democrática do Congo, doravante RDC) durante um trabalho de campo realizado em duas províncias do norte de Angola: Cabinda e Lunda Norte. A definição destes locais para realização do trabalho de campo resultou de um diálogo com o Serviço Jesuíta para Refugiados (JRS) de Angola, organização que atua como "parceiro operacional" (implementing partner) do Alto Comissariado das Nações Unidas para Refugiados (ACNUR) no país. O próprio acesso a refugiados de uma forma geral, não só em Angola, mas em qualquer país, é normalmente mediado por estas organizações (ACNUR mais um "parceiro operacional" por país), que detêm o controle sobre os registros de solicitações e concessões do status de refugiado, bem como executa projetos e programas de acompanhamento e assistência dos mesmos.

Recebi as primeiras orientações por parte do staff do escritório central do JRS em Luanda em um briefing, onde me foi exposto quais eram as "situações de refúgio" na Lunda Norte e em Cabinda, que eram então os únicos escritórios descentralizados em atividade no país ${ }^{3}$. A noção de "situação de refúgio" é constitutiva do campo semântico das políticas para refugiados, aparecendo com frequência em documentos e estudos institucionais para descrever as condições socioeconômicas de campos e comunidades de refugiados, especialmente no que se refere a "situações de refúgio prolongadas" (protracted refugee situations ${ }^{4}$. A diferença entre as "situações" nas duas províncias que visitei, segundo os relatos preliminares do JRS, era de que em Cabinda, por estarem em menor número, os refugiados já estariam mais "integrados" à sociedade local, enquanto na Lunda Norte, por serem uma grande comunidade, estariam enfrentando muita resistência, discriminação e conflitos nas relações com grupos locais.

2 Realizado entre setembro e novembro de 2011 como parte de minha pesquisa de doutoramento, com apoio do ACNUR através de seu Small Grants Program para pesquisas de curta duração.

3 Em 2011 o JRS ainda contava com um escritório em Malanje, destinado a atender os fluxos de refugiados que entram no país pela fronteira de Maquela do Zombo, no Uíge, mas que já se encontrava em vias de desativação e não realizava nenhuma atividade.

4 Situações de refúgio prolongado se referem sobretudo a campos e comunidades de refugiados que se mantém no país de acolhida com o status de refugiados para além dos prazos de resolução formal dos conflitos que caracterizavam crises humanitárias em seu país de origem. O prolongamento da "situação de refúgio" se deve a perseguições e conflitos particulares em determinadas regiões ou relativos a determinados grupos aos quais pertencem os refugiados nestas situações. 


\section{Imagem 1 - Mapa de Angola}

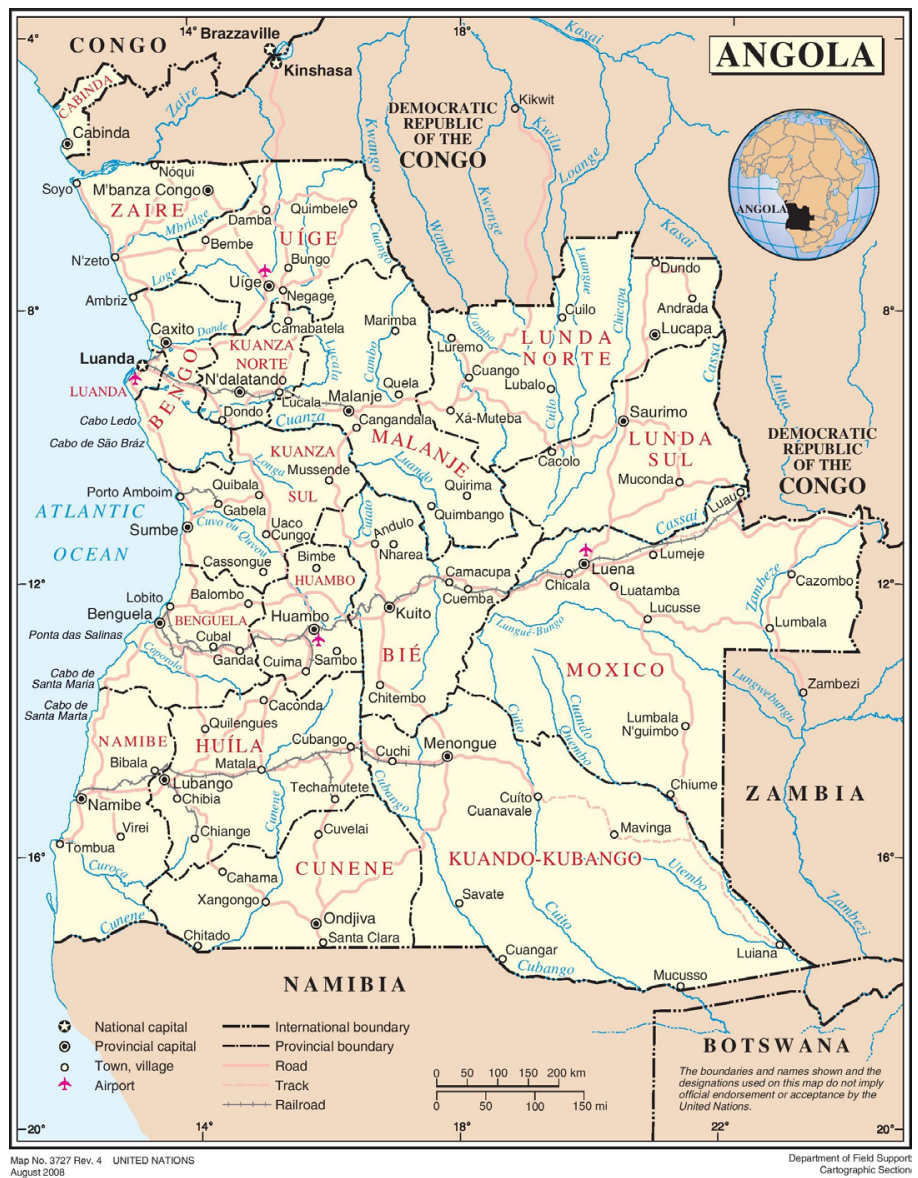

Fonte: ACNUR, 2005. Disponível em: <http://www.refworld.org/docid/4937c7b50.html>.

A análise de "situações de refúgio" se aproxima, assim, da própria prática de avaliação das políticas, programas e projetos implementados pelos parceiros operacionais do ACNUR, tendo em vista sua maior ou menor eficácia como promotores da "integração" ${ }^{5}$ de refugiados. O refugiado é situado, assim, em relação a determinadas metas traçadas tanto em termos orçamentários e

\footnotetext{
5 A noção de integração pode ser muito variada, e tentativas de estabelecimento de critérios universais para se considerar um imigrante integrado tendem a se confrontar com a diversidade de experiências de recepção de refugiados de diferentes origens em diferentes lugares do mundo. Relatórios destas experiências podem ser encontradas na série de working papers do ACNUR, New Issues in Refugee Research (disponível no site da organização, <www.unhcr.org >). Para sistematizações mais panorâmicas destas experiências e noções de "integração" de refugiados, ver CRISP, Jeff. The local integration and local settlement of refugees: a conceptual and historical analysis, e FIELDEN, Alexandra. Local integration: an under-reported solution to protracted refugee situations.
} 
quantitativos do número de beneficiários atendidos quanto de sua inserção em postos de trabalho e de moradia, principalmente. A "integração" é atingida, assim, quando a correlação entre estes dados deixa de justificar a alocação de recursos para a execução de ações especificas junto a refugiados em determinadas regiões. Neste sentido, a explanação sobre as situações de refúgio em Cabinda e na Lunda Norte subentendia a sugestão de que a pesquisa deveria ser realizada preferencialmente na Lunda Norte, onde as atividades do JRS eram mais visíveis e volumosas, e por isso com um potencial maior de geração de dados qualitativos que pudessem ser traduzidos em alguma forma de avaliação das próprias políticas executadas pela organização ${ }^{6}$.

Acepções etnográficas clássicas da noção de "situação" podem ser operacionalizadas para a compreensão do que constitui a noção de "situação de refugiado" ou "situação de refúgio". Conceituando a noção de situação social Gluckman ${ }^{7}$ abordou os interesses expressos por diferentes grupos a respeito de um projeto específico (a construção de uma ponte) em um evento (a inauguração da ponte), sem se concentrar sobre o significado disso para uma cosmologia específica. Isto representou uma inovação na forma de conceber unidades de análise em antropologia, deslocando o foco das descrições etnográficas de comunidades, etnias ou grupos de interesse em si para as relações, conflitos e alianças que emergem em ocasiões de encontro entre grupos distintos. Analisar situações sociais significa, assim, buscar entender como diferentes atores se situam uns com relação aos outros ao negociar posicionamentos e apoios políticos.

Igualmente relevante para a análise de "situações de refúgio" para além das formas de enquadramento dos sistemas de proteção e assistência a refugiados é a ideia de análise situacional proposta por Elias e Scotson ${ }^{8}$ para a análise de conflitos socialmente construídos como oposições entre "estabelecidos e outsiders". Esta perspectiva busca a compreensão de como características e aspectos atribuídos ao outro evidenciam diferenças e desigualdades entre grupos em um mesmo contexto socioespacial, deslocando o foco da análise sociológica clássica das estruturas permanentes como parâmetro para a detecção de comportamentos desviantes ou anômicos para uma abordagem que busca compreender como cada grupo constrói a si através do contraste com os atributos de seus "outros".

Em seu estudo sobre o significado das migrações no noroeste da Zâmbia, Barret ${ }^{9}$ aponta a importância de se inscrever o deslocamento experienciado por

6 BAKEWELL, Oliver. Breaching the borders between research and practice: development NGOs and qualitative data.

7 GLUCKMAN, Max. Análise de uma situação social na Zululândia moderna.

8 ELIAS, Norbert, SCOTSON, John. Os estabelecidos e os outsiders: sociologia das relações de poder a partir de uma pequena comunidade.

9 BARRETT, Michael. Social landscapes and moving people: the mysterious meaning of migration in western Zambia. 
refugiados no contexto mais amplo dos espaços de mobilidade entre lugares e culturas em determinados contextos. A relevância do estudo das "situações de refúgio" como objeto da pesquisa socioantropológica reside, assim, na possibilidade de compreensão do processo de construção social de noções do que seja um refugiado em diferentes contextos, algo que não necessariamente se configura em função do status jurídico de refugiado ou de requerente de asilo. Outras formas de reconhecimento de imigrantes e refugiados por seus "outros" ou como um "outro" produzem experiências relativas à interação entre identidades socioculturais que singularizam a experiência de "ser refugiado" em determinados contextos.

Analisar diferentes noções de refugiado levando em conta como os sujeitos assim classificados se inserem nos contextos onde vivem implica em um descentramento em relação à definição formal do status jurídico, do contrário arriscando reduzir processos e experiências múltiplas de deslocamento a agrupamentos de pessoas de acordo meramente com o tipo de assistência que recebem. Isto não significa ignorar que "classificações têm consequências na vida real"10, mas sim reconhecer que o "agenciamento não é um processo de mão única"11. Ao invés de me perguntar se refugiados estão, de fato, integrados à sociedade de acolhida, entendo que a pergunta relevante, desta perspectiva, é: como refugiados se situam e são situados com relação a seus interlocutores individuais, coletivos e institucionais - nos contextos em que se inserem?

Aoformular esta questão, pressuponho que o referencial de enquadramento fornecido pelas categorias da política global conduzida pelo ACNUR produz configurações de relações sociais similares nos diferentes contextos geopolíticos onde é implementada. A análise de "situações" vividas por refugiados é, neste sentido, necessariamente comparativa, permitindo compreendermos como as práticas e categorias socioculturais próprias dos contextos onde estas políticas são implementadas se articulam com o aparato político e conceitual das instituições que as implementam. Neste artigo, especificamente, procuro explicar como uma categoria das políticas de proteção de refugiados - a de "situação de refúgio" - abarca diferentes sentidos da experiência de inserção de refugiados em um país de acolhida, mas não abordo categorias e práticas que remetem às relações interétnicas entre congoleses e angolanos. Minha análise está, portanto, focada nas interações que meus interlocutores estabelecem a partir de um investimento em sua "posição de sujeito"12 de refugiados. Análises de outras dimensões identitárias - culturais, econômicas e religiosas, por exemplo - podem ser complementares a ela, mas não serão realizadas aqui.

\footnotetext{
${ }^{10}$ COLSON, Elizabeth. Forced Migration and the anthropological response, p. 3.

${ }^{11}$ ZETTER, Roger. More labels, fewer refugees: remaking the refugee label in an era of globalization, p. 186.

${ }^{12}$ MOORE, Henrietta. Fantasias de poder e fantasias de identidade: gênero, raça e violência, p. 36.
} 


\title{
Refugiados na Lunda Norte: aldeias e comunidades
}

O trabalho de campo junto aos refugiados assistidos pelo JRS em Angola aconteceu em duas fases. Na primeira participei ${ }^{13}$ de uma expedição do JRS de dois dias por terra até o Dundo, capital da Lunda Norte, região nordeste de Angola, onde permaneci por cerca de vinte dias no escritório regional do Dundo, que á época atendia também os refugiados e requerentes de asilo residentes na Lunda Sul. A segunda fase consistiu em uma viagem a Cabinda, na região noroeste, que abordarei mais adiante. Na chegada ao Dundo passamos em frente a um centro de detenção para o qual normalmente eram enviados estrangeiros em situação ilegal, administrado pelo Serviço de Migração e Estrangeiros $(\mathrm{SME})^{14}$, evocando nos funcionários do JRS, casos de detenção irregular de refugiados em que a organização teve que intervir. Antevendo relatos similares por parte dos refugiados que visitaríamos nos dias seguintes, um dos funcionários me advertiu da seguinte forma:

\begin{abstract}
É preciso ter jeito para trabalhar com refugiados. Tem que mostrar que está preocupado com os problemas deles. Se já chega arrogante ou com uma prioridade sua junto aos refugiados, eles te enchem de reclamações. Se prepare, pois na primeira vez que eles te virem, vão te flagelar.
\end{abstract}

O escritório do JRS no Dundo atendia refugiados e requerentes de asilo localizados em dois assentamentos em distritos próximos, além de alguns indivíduos e famílias que residem em bairros periféricos do centro urbano da cidade. O maior dos assentamentos fica no distrito de Nzagi, município de Cambulo, a cerca de noventa quilômetros do centro urbano do Dundo, onde residiam entre oitocentas e mil pessoas. No distrito de Candjamba, município de Chitato, a vinte quilômetros da capital, ficava outro assentamento, cuja população variava entre trinta e cinquenta pessoas. Mais de noventa por cento dos refugiados e requerentes de asilo alocados no Dundo eram provenientes da RDC, e o restante era formado por pequenos grupos e indivíduos de outros países da África central e ocidental, tais como República do Congo (CongoBrazzaville), Ruanda, Uganda, Serra Leoa, Costa do Marfim e Mauritânia. Embora houvesse uma certa mobilidade de refugiados que optavam por residir na zona urbana do Dundo, principalmente saídos do assentamento de Candjamba, todos os refugiados se apresentavam, e eram reconhecidos pelas instituições, como membros de um dos assentamentos.

O assentamento de Nzagi formou-se a partir de 1997 com o agrupamento de cerca de seiscentos congoleses que migraram para Angola ao longo da

\footnotetext{
${ }^{13}$ A expedição já estava programada, e tinha como meta realizar levantamentos de solicitações de asilo em outras localidades da Lunda Norte e da Lunda Sul, avaliando a necessidade de instalação de novos escritórios provinciais na região.

${ }^{14}$ Agência estatal vinculada ao Ministério do Interior, responsável pelos trâmites de concessão e verificação de passaportes, vistos e salvo-condutos nas fronteiras angolanas.
} 
guerra pela sucessão do poder na RDC (1996-1998), oriundos sobretudo das províncias do Kasai e de Katanga, que fazem fronteira com a Lunda Norte ${ }^{15}$. Até 1999, o assentamento do Nzagi recebia suporte da Federação Luterana Mundial (WLF) e da Organização das Nações Unidas para a Alimentação e Agricultura (FAO). Segundo relatos de refugiados que estão no Nzagi desde sua formação, entre 1999 e 2004 a comunidade permaneceu completamente sem amparo de organizações internacionais até que um funcionário do Comitê Internacional da Cruz Vermelha (CICV), que verificava o estado das aldeias angolanas no pós-guerra notificou sua presença para o escritório do JRS que havia sido recém instalado na província do Moxico (na fronteira com a Zâmbia, ao sul das Lundas) para o repatriamento de refugiados angolanos exilados na Zâmbia. Através do JRS e do ACNUR, os refugiados do Nzagi passaram a receber doações de comida e roupas, além de se tornarem elegíveis para receberem folhas de zinco e barrotes do governo angolano para a construção de casas. $\mathrm{O}$ escritório do JRS no Dundo foi criado em 2008, mesmo ano em que se iniciou o assentamento de refugiados no Candjamba, em um esforço de distribuição do crescente número de refugiados que iam se acumulando no Nzagi.

Durante as primeiras incursões nas comunidades, todos os refugiados com que conversei, individualmente ou em pequenos grupos, retomavam problemas e dificuldades vividas nos assentamentos já relatados ao JRS. O "flagelo" do qual me havia prevenido o funcionário da organização se referia, assim, à repetição de queixas e pedidos urgentes que o JRS recebia constantemente, cujo encaminhamento, no entanto, se mostrava moroso em função de tramitações burocráticas e da necessidade de superação de entraves de ordem política. A presença de um elemento novo junto à equipe do JRS, branco e estrangeiro, apresentava-se como uma nova frente de apresentação das demandas coletivas e individuais dos refugiados.

As reclamações e demandas relatadas de forma mais imediata pelos refugiados giravam em torno da obtenção de documentos nacionais de identidade para refugiados como um fator condicionante para a obtenção de outros direitos, desde o de receber auxílios governamentais para a compra de alimentos para crianças até autorizações para trabalhar no país. Segundo estimativas dos agentes do JRS, não mais do que vinte por cento das pessoas atendidas pelo JRS/ACNUR em Angola dispunham do cartão do Comitê de Reconhecimento do Direito de Asilo (COREDA), que é a documentação definitiva que resulta do reconhecimento do status de refugiado no país. A grande maioria permanece no país com recibos do pedido de asilo emitidos

\footnotetext{
15 A coletânea organizada por CLARK, John. The African stakes in the Congo war, oferece um importante panorama histórico e sociológico destes conflitos na RDC. Sobre as dinâmicas dos deslocamentos forçados internos e transfronteiriços, ver MURISON, Jude. The politics of refugees and internally displaced persons in the Congo War, no mesmo volume.
} 
pelo SME e com declarações provisórias emitidas pelo próprio JRS por delegação do ACNUR. Há, também, imigrantes indocumentados aguardando audiência ${ }^{16}$ para realizar o pedido formal de asilo e obter o recibo, que são cadastrados como "pessoas de interesse" do programa de assistência a refugiados.

A reclamação que ouvi com mais frequência dos refugiados dizia respeito à renovação ad infinitum dos recibos do SME. Fisicamente, o recibo é uma folha de papel tamanho ofício onde consta uma declaração impressa de três linhas, seguida da assinatura de um agente do SME e uma sequência de quadrados reservados para os sucessivos carimbos de renovação do recibo que o requerente de asilo deve realizar a cada seis meses. Um homem congolês me mostrou seu recibo com mais de vinte carimbos, o que significa que ele estava havia, pelo menos, dez anos renovando seu status de requerente de asilo sem qualquer perspectiva ou informação segura de que sua solicitação pudesse ser apreciada pelo COREDA. Além disso, estava seriamente preocupado com a falta de espaço no papel para novos carimbos - que já haviam extrapolado os quadrados reservados para isso - uma vez que a renovação do recibo poderia deixa-lo, por tempo indeterminado, sem qualquer documento válido que comprovasse sua condição de requerente de asilo.

A tríade de documentos dos refugiados - a declaração, o recibo e o cartão - representam um caminho para sua regularização no país. Para a maioria dos requerentes de asilo a declaração do JRS é o primeiro papel que recebem depois de entrar no país, e é o papel que devem apresentar ao SME como solicitação formal de asilo no país, entregando-a com uma foto anexada, obtendo em troca o recibo. A foto e a declaração recebidas pelo SME são encaminhadas para o Ministério da Justiça, ao qual o COREDA está subordinado, entrando na fila dos processos de RSD.

O COREDA é composto por representantes do Ministério da Justiça, que o preside, do Ministério do Interior, do Ministério de Assistência e Reintegração Social (MINARS), do SME, da Polícia de Fronteira e de organizações da sociedade civil sem direito a voto, que é ocupada por representantes do JRS e do escritório nacional do ACNUR. Segundo os funcionários do JRS, os pedidos de asilo são sistematicamente rejeitados pelo COREDA em sua primeira apreciação, abrindo prazo para apresentação de recursos circunstanciados. A segunda apreciação de um mesmo pedido de asilo é, então, acompanhada de documentos narrativos baseados nas declarações particulares dos requerentes que comprovem que sua imigração foi motivada por um "fundado temor de perseguição".

${ }_{16}$ Para ser encaminhado diretamente para análise do COREDA a solicitação de asilo deve ser feita no posto de fronteira por onde o imigrante ingressa no país. Por receio de refoulement ("devolução" de solicitantes de asilo ao país de proveniência, prática ilegal a partir da Convenção de Genebra), muitos imigrantes optam por ingressar no país sem papeis e somente posteriormente, por indicação de parentes e amigos, procuram as representações do ACNUR. 
O problema que o pedido de segunda via do recibo representa para os requerentes de asilo se relaciona com o momento de reconstrução do aparelho estatal e da consequente incipiência das rotinas de registro e protocolo documental nas instituições governamentais angolanas, sobretudo nas províncias do interior do país, que resulta, de forma mais intensa para imigrantes, mas inclusive para cidadãos nacionais, em uma fetichização do documento. Ou seja, tanto a declaração quanto o recibo são concebidos como o reconhecimento do status jurídico de requerente de asilo em si, e não como documentos comprobatórios.

A obtenção do recibo do SME é experienciada pelos requerentes de asilo como uma transação de papeis. O requerente entrega a declaração do JRS em troca do recibo, o que representa um passo em direção à obtenção do cartão. O pedido de asilo não é considerado formalizado, no entanto, enquanto a declaração, junto com outros documentos apensados por advogados do JRS, não é protocolada pelos órgãos centrais. O protocolo não é recebido pelo requerente individualmente, mas pelo JRS, que segue a prática recomendada pelo ACNUR de entrar com processos e recursos coletivos como uma estratégia de caracterização dos movimentos migratórios de uma determinada região como resultado de crises humanitárias ou instabilidades políticas que favoreçam o reconhecimento do status de refugiado.

A centralização do procedimento formal de pedido de asilo faz dos recibos emitidos nas províncias uma forma de averbação de que a transação de papeis foi realizada, mas não necessariamente é acompanhada de registro e controle formal nas províncias, pois o processo só se torna existente quando é protocolado em Luanda. Não havendo registro sistemático também não há uma base que possa ser consultada para a emissão de uma segunda via do recibo, a não ser a do JRS, que nestes casos emite uma nova declaração, que pode ser trocada por um novo recibo. Ou seja, do ponto de vista dos requerentes de asilo, a necessidade de uma segunda via representa o risco de se ter que reiniciar o processo de solicitação de asilo, demorando ainda mais para obter o cartão do COREDA.

A ênfase nas demandas pelo cartão do COREDA não significa que as vulnerabilidades, inseguranças e conflitos experienciados pelos refugiados resultasse unicamente da inconsistência dos documentos provisórios. Segundo relatos de refugiados, em ocorrências como detenções pela polícia ou em disputas com grupos de aldeias vizinhas, eles são frequentemente interpelados como "zairenses" e "langas"17, categorias que marcam sua condição de outsiders em relação à vida econômica e política nacional, reproduzindo uma lógica de

\footnotetext{
17 A palavra Zairense é o gentílico para o cidadão da República do Zaire, denominação que teve a RDC entre 1971 e 1997, por decreto do então governante general Mobutu, que visava substituir nomes atribuídos pela ou alusivos à colonização belga para nomes considerados africanos, inclusive nomes pessoais. Langa refere-se ao lingala, língua franca do tronco banto falada em grande parte da RDC e em países vizinhos como no Congo-Brazzaville e no Gabão.
} 
segregação e criminalização das migrações a partir de discursos centrados nos valores da "segurança" e do "desenvolvimento" nacionais. Ou seja, nestes casos o status de refugiado é subsumido a seu reconhecimento como estrangeiros, e são necessárias intervenções do JRS para evitar deportações e prisões de refugiados, restaurando, ainda que provisoriamente, sua diferenciação em relação a imigrantes indocumentados ou "econômicos".

\section{Refugiados em Cabinda: um indivíduo e sua família}

Na segunda fase do trabalho de campo junto a refugiados em Angola permaneci por cerca de vinte dias em Cabinda, também no escritório provincial do JRS, após retornar da Lunda Norte para Luanda. Em Cabinda, conforme me haviam advertido os funcionários do JRS em reuniões prévias à expedição para o Dundo, o número de refugiados atendidos era dramaticamente menor, o que justificaria uma atenção maior aos refugiados do Dundo. Em Cabinda eram atendidos pelo JRS vinte refugiados, dos quais doze pertenciam a uma única família de congoleses da RDC. À época em que realizei este trabalho de campo, o escritório do JRS em Cabinda aguardava a decisão do escritório central e do próprio ACNUR a respeito de sua renovação para o ano seguinte levando em conta não somente o trabalho com refugiados, como também a assistência a angolanos em processo de retorno voluntário dos campos de refugiados da $\mathrm{RDC}^{18}$.

Diferentemente da Lunda Norte, onde a história da formação das comunidades de refugiados é narrada como um deslocamento massivo de pessoas, a história dos refugiados sob a política de proteção do ACNUR em Cabinda confunde-se com a narrativa da primeira pessoa a ter o status de refugiado reconhecido em Cabinda: S. M. ${ }^{19}$ nasceu em Bakwanga (atual MbujiMayi), capital administrativa e polo diamantífero da província do Kasai Oriental, sudeste da RDC. Seu pai pertenceu à primeira geração de trabalhadores das minas de diamantes exploradas por mineradoras belgas, no final dos anos 1940, que extraíam diamantes de aluvião do rio Bakwanga, tributário do rio Cassai, cuja corrente era responsável pelo arrasto de diamantes oriundos de jazidas subterrâneas localizadas em áreas hoje situadas nas províncias angolanas da

${ }_{18}$ Entre 1961, quando se iniciou o processo de luta armada pela independência de Angola, e 2002, quando findou a guerra civil angolana, cerca de duzentos mil angolanos se deslocaram para a RDC através da fronteira norte do país. O governo congolês adotou o modelo de campos de refugiados fechados e geridos diretamente por juntas formadas pelo ACNUR e pelo governo congolês. Sobre os campos de refugiados angolanos na RDC, ver TALLIO, Virginie. La construction de la catégorie "réfugié" dans un camp en R.D.C.: rôle de l'institution, stratégies des exilés et place du chercheur.

${ }^{19}$ Apesar de ser um caso notório em Cabinda, optei por preservar seu nome uma vez que o este artigo se destina a ampla divulgação. Alguns aspectos e detalhes de sua trajetória também foram modificados ou omitidos pela mesma razão. 
Lunda Norte e da Lunda Sul. Em 1955, às vésperas da eclosão dos movimentos de reivindicação de independência pelos movimentos nacionalistas congoleses, sua família se mudou para Elizabethville (hoje Lubumbashi), capital da província de Katanga. À época também surgiam os primeiros movimentos pela separação da região em relação ao resto do país, primeiramente reivindicando o reconhecimento do Estado Autônomo do Kasai, e mais tarde, sob a liderança do líder lunda Moise Tshombé, declarando a independência de Katanga.

Entre 1956 e 1960 o Estado belga reprimiu as migrações internas, numa tentativa de impedir a articulação e unificação das bases políticas com aspirações separatistas das províncias do sudeste. A família de S. M., juntamente com diversas outras pessoas, ao ser identificada como originária do Kasai Oriental, foi então forçada a retornar a Bakwanga para não serem enquadrados como "terroristas" ligados à guerrilha katanguesa. Após a independência e renomeação do país de Congo Belga para República Democrática do Congo (RDC), em julho de 1960, visando manter o monopólio sobre a extração diamantífera na região, a Bélgica passa a apoiar as guerrilhas separatistas baseadas em Elizabethville, em um cenário no qual o governo recém instaurado tinha poucas condições de exercer controle militar sobre a região.

O apoio ocidental, representado pela Bélgica, aos separatistas katangueses motivou o governo congolês (já reformulado pela ascensão do general Joseph Mobutu ao cargo de primeiro-ministro no lugar de Patrice Lumumba, que foi assassinado) a buscar apoio soviético para retomar o controle, ao mesmo tempo em que denunciou a Bélgica na ONU por estender sua presença colonizadora no país com a finalidade de se manter no monopólio da extração de minérios. Quando Mobutu assume o poder com um golpe de Estado, assumindo a presidência no lugar de Kasavubu, em 1966, Katanga e Kasai já eram novamente províncias congolesas governadas por pessoas ligadas a Mobutu. O regime ditatorial é mantido até cerca de 1989, quando se inicia um movimento de abertura de regime representado por uma série de medidas, entre elas a convocação de eleições e de uma Conferência Nacional para debater uma reforma política.

Nas eleições realizadas em 1992, elegeu-se primeiro ministro Étienne Tshisekedi pelo partido Union pour la Democratie e le Progrés Social (UDPS), cuja base eleitoral era sua província natal, o Kasai Oriental. No ano seguinte, no entanto, Mobutu demite Tshisekedi do cargo, imediatamente voltando a acumulá-lo, e depois o entregando a pessoas de sua confiança e de menor expressão política. Nos anos finais de Mobutu, um novo golpe de Estado liderado por Laurent-Desirée Kabila - um ex-guerrilheiro anticolonialista exilado na Tanzânia - já estava em curso. Com a Morte de Mobutu em 1997, Kabila se autodeclara o novo presidente, contando com o apoio das forças militares, e novamente com a oposição de Tshisekedi. 
Nos anos 1990, S. M. trabalhava como contabilista em Kinshasa. Durante a Conferência Nacional de 1992, sua esposa retornava de uma viagem ao Kasai Oriental trazendo uma carta endereçada a Tshisekedi enviada por um amigo em comum. A carta foi encontrada e confiscada em uma revista policial, resultando na inclusão de S. M. e sua esposa no rol de pessoas monitoradas pela polícia política. Após a ascensão de Kabila, em 1997, as perseguições a apoiadores de Tshisekedi se intensificaram, e em maio de 1998, S. M. e a esposa foram detidos e torturados por policiais à paisana, causando a morte dela. Alguns meses depois, no mesmo dia em que apresentou uma queixa formal a um tribunal militar em Kinshasa, S. M. partiu levando seus seis filhos para o vizinho Congo-Brazzaville, onde permaneceram quatro anos. Durante este tempo remeteu uma série de cartas à UNICEF, solicitando ajuda humanitária, às organizações Voix des Sans Voix (VSV) e Organização Mundial Contra a Tortura (OMCT), e a diversas embaixadas de países ocidentais (foram citados Estados Unidos, Canadá, Suíça, Bélgica e França) em Kinshasa, denunciando as torturas e perseguições pelas quais havia passado.

Em 2001, o dono da lan house onde S. M. havia imprimido uma destas cartas em Brazzaville, gravou o arquivo e o vendeu para informantes da polícia política da RDC no Congo-Brazzaville, gerando novas perseguições a ele e a seus filhos. S. M. então solicitou asilo ao escritório do ACNUR em Ponta Negra, expressando o objetivo de ser realocado para o Canadá, onde tinha contatos que o poderiam apoiar. Entretanto, um mês após a cessação da guerra civil angolana em 2002, S. M. e sua família foram enviados para Cabinda, que fica a cerca de trinta quilômetros de Ponta Negra. No mesmo ano S. M. teve seu estatuto de refugiado formalmente reconhecido pelo COREDA, estendido também aos filhos e demais familiares que haviam migrado junto com ele.

Em 2011, quando o conheci, S. M. já contava com um terreno na aldeia do Buco ggoyo $^{20}$, cerca de vinte quilômetros do centro urbano da cidade de Cabinda, e aguardava a liberação dos tijolos e barrotes para iniciar a construção de sua casa própria, todos cedidos pelo MINARS. Poucos anos antes havia se casado novamente, com uma mulher cabinda. Seu filho mais novo havia logrado trazer a mulher, filhos e sogra da RDC para Cabinda, os quais também tiveram reconhecido o status de refugiados, restando apenas receber os documentos do COREDA. Em seus relatos sobre dificuldades de "integração" e demandas direcionadas ao JRS, entretanto, S. M. e seus filhos ressaltavam a dificuldade de obtenção de emprego por serem estrangeiros, e mais ainda por serem "zairenses", ou seja, imigrantes oriundos da RDC. Nas palavras

\footnotetext{
${ }^{20}$ Em uma área que havia sido destinada pelo MINARS para o reassentamento de pessoas em situação "vulnerável", que incluía angolanos retornados dos campos de refugiados da RDC e grupos desalojados por obras de construção civil em aldeias e bairros periféricos da cidade de Cabinda. S. M. e sua atual esposa foram os únicos estrangeiros assentados nesta área.
} 
do próprio S. M., o estatuto de refugiado em Angola "dá direito a emprego, mas não dá emprego", querendo dizer que, embora a legislação angolana preveja aos refugiados estatutários os mesmos direitos dos cidadãos nacionais, este direito esbarra em preconceitos para com imigrantes de uma forma mais ampla, independentemente de seu status jurídico.

\section{Para além do status jurídico: o que é um refugiado?}

As duas narrativas que acabei de apresentar relatam duas situações distintas vividas por refugiados congoleses em duas províncias do norte de Angola. Argumento, aqui, com base nos aportes de Gluckman e Elias já explicitados no início do artigo, que a noção de situação não se refere a uma condição estática, mas a um constante situar-se por parte dos interlocutores da pesquisa. A dinâmica específica de cada situação atribui sentidos diferentes à experiência dos sujeitos classificados como refugiados, e, portanto, confere significados diferentes à categoria que os classifica e insere no ordenamento sociojurídico angolano. Ou seja, embora trate-se de refugiados reconhecidos a partir dos mesmos critérios e princípios jurídicos e políticos em ambos os casos, o modo como se produziram estes enquadramentos geraram experiências distintas também por parte da chamada sociedade local e das instituições ao longo do processo de Determinação do Status de Refugiado (RSD, para Refugee Status Determination).

A relação entre o solicitante de refúgio, as instituições que operam o RSD e a sociedade de acolhida se estrutura segundo a mesma lógica que resulta na eficácia simbólica da cura xamânica como proposta por Lévi-Strauss ${ }^{21}$. Para a atribuição do estatuto de refugiado ser levada a termo, as desordens experienciadas pelo solicitante de asilo - o temor de perseguição e a migração forçada - precisam ser detectadas e materialmente comprovadas pelo sujeito mediador, papel que é desempenhado pelos comitês de reconhecimento compostos pelo ACNUR, entidades governamentais do país concedente de asilo, e de organizações representantes da sociedade civil. Ao ter reconhecido o status jurídico, o refugiado é considerado reinserido a uma "ordem nacional das coisas", ou seja, está novamente enquadrado a partir de um conjunto de pressupostos jurídicos e políticos que regulam e documentam sua vida social, centralizados pelo aparato institucional de um Estado-nação ${ }^{22}$.

A reflexão de Valluy ${ }^{23}$ sobre sua experiência como jurado de uma comissão de avaliação de solicitações de asilo na França revela o funcionamento do processo de RSD como uma arena de disputas não somente a respeito do mérito de cada pedido particularmente, mas de forma mais ampla sobre

\footnotetext{
${ }^{21}$ LÉVI-STRAUSS, Claude. O feiticeiro e sua magia.

${ }^{22}$ Cf. MALKKI, Liisa. Purity and Exile: violence, memory, and national cosmology among Hutu refugees in Tanzania.

${ }^{23}$ VALLUY, Jerôme. Rejet des exilés: le grand retournement du droit de l'asile.
} 
que tipo de pessoa mereceria o acolhimento como refugiado pelo país. Ao avaliar sucessivas solicitações de refúgio, a comissão da qual o autor fazia parte retomava debates de escala nacional a respeito das políticas nacionais de repressão às migrações e controle das fronteiras, nos quais representantes de determinadas instituições estatais e representantes da sociedade civil assumiam posições antagônicas ao defenderem, os primeiros, medidas repressivas e a criminalização dos movimentos migratórios e, os segundos, medidas receptivas e a criação de políticas de apoio a imigrantes.

Tais posicionamentos, que se reproduzem amplamente em debates sobre politicas migratórias ao redor do mundo, fundamentam-se sistematicamente em preconcepções de quais sejam as motivações para pessoas migrarem, e que se apresentam, nas mídias e em discursos oficiais, como uma dicotomia: o medo e o dinheiro. Tanto os processos de RSD quanto a recepção de solicitações de asilo nas fronteiras e em postos de atendimento das organizações credenciadas pelo ACNUR são informados por relatórios e análises de conjuntura que classificam determinados lugares como assolados por crises humanitárias, instabilidades políticas e condições de insegurança generalizada que fundamentam e justificam, a priori, o temor como motivação para migrar ${ }^{24}$. Nestes casos, o requerente de asilo é enquadrado como tal a partir de um reconhecimento prima facie que assume como evidência suficiente para o reconhecimento do imigrante como requerente de asilo sua proveniência de lugares reconhecidamente afetados por crises humanitárias, independentemente de quaisquer razões particulares. A expressão do "temor" ou "medo" de permanecer em seu local de origem é, assim, o elemento que diferencia refugiados legítimos do "imigrante econômico", que teria como principal motivação para migrar acumular dinheiro para remeter a seu país.

O reconhecimento prima facie de refugiados é um tema controverso no campo jurídico dos refugee studies, pois, como dispositivo jurídico não codificado pelo direito internacional, atua na transferência de poder e controle sobre populações dos Estados que constituem os circuitos migratórios para o sistema de proteção regulado pela Convenção de Genebra ${ }^{25}$. Ou seja, opera como um prejulgamento do direito de asilo nos procedimentos de cadastro e inclusão de imigrantes como beneficiários da assistência a refugiados, autenticando demandas individuais fundamentado em representações coletivas sobre as populações migrantes.

\footnotetext{
${ }^{24}$ A Convenção de Genebra diz que um refugiado é qualquer pessoa que "devido a fundado temor de perseguição por motivos de raça, religião, nacionalidade, grupo social ou opiniões políticas, se encontra fora do país de sua nacionalidade e que não pode ou, em virtude desse temor, não quer valer-se da proteção desse país". Cf. UNHCR. Convention and protocol relating to the status of refugees (1951/1967).

${ }^{25}$ Cf. ALBERT, Matthew. Prima facie determination of refugee legal status: an overview of its legal foundation e RUTINWA, Bonaventure. Prima facie status and refugee protection.
} 
A controvérsia em torno do reconhecimento prima facie de refugiados contrapõe duas concepções do que seja um refugiado, agenciando diferentes interpretações dos instrumentos jurídicos reguladores do processo de RSD e da política global de proteção a refugiados. Tais concepções se traduzem em diferentes representações que diferenciam refugiados com o mesmo status jurídico pelas figuras do "refugiado humanitário" e do "exilado", associando o primeiro a imagens midiáticas de campos caracterizados pela homogeneidade da paisagem composta pelas barracas fornecidas pelo ACNUR, por estações de distribuição de água, roupas e comida, e pela miséria resultante de guerras e conflitos ao redor do planeta; e associando o segundo primariamente a suas posições e atuação política individual, por exemplo, em movimentos e partidos de oposição a determinados regimes de governo e na militância e defesa de direitos humanos.

$\mathrm{O}$ atendimento a refugiados em situações de "crise humanitária" visa restabelecer condições mínimas de sobrevivência através do fornecimento de moradia, água, comida e roupas, reduzindo a população atendida ao que Malkki ${ }^{26}$ descreve como um "mar de humanidade", ou seja, a uma massa política e culturalmente indiferenciada de pessoas cuja demanda essencial presumida e assumida como responsabilidade pelas organizações que as governam é a manutenção e preservação de seus corpos como condição mínima de humanidade no que Agamben ${ }^{27}$ chama de "mera vida ${ }^{28 "}$ (bare life). A desconsideração sistemática das histórias de vida de sujeitos recipientes de assistência humanitária é defendida e reproduzida por funcionários e gestores de organizações internacionais como um mecanismo de imparcialidade da "governança humanitária" e como uma forma de prevenção de conflitos e disputas por recursos em campos de refugiados ${ }^{29}$.

$\mathrm{Na}$ prática, a diferença entre sujeitos representados como refugiados humanitários ou exilados reside no espaço de expressão e atenção às histórias de vida individuais de refugiados. Em Cabinda, a história de S. M. era conhecida não somente pelos funcionários do JRS, mas também por agentes de outras instituições envolvidas no campo de atenção aos imigrantes, tais como o SME e o MINARS, bem como por muitos de seus vizinhos e outras pessoas nos espaços

\footnotetext{
${ }^{26}$ MALKKI, Liisa. Speechless emissaries: refugees, humanitarianism, and dehistoricization.

27 AGAMBEN, Giorgio. Homo Sacer: o poder soberano e a vida nua.

${ }^{28}$ A palavra bare é usada coloquialmente na língua inglesa para se referir a partes do corpo nuas. Em que pese o propósito literário que a expressão "vida nua" confere ao trabalho de Agamben, entendo que seu propósito é demonstrar que a política humanitária nos campos de refugiados opera segundo um imperativo de manutenção de corpos meramente funcionais (remetendo ao conceito de biopolítica), com pouca ou nenhuma perspectiva desse voltarem para outras dimensões dos direitos humanos (direitos sociais, culturais, ambientais, etc.). Ou seja, os corpos não podem estar nem mais nem menos do que vivos, por isso entendo ser mais precisa a expressão "mera vida".

${ }^{29} \mathrm{Cf}$. AGIER, Michel. Le gouvernement humanitaire et la politique des réfugiés.
} 
por onde circulava. Em suas incursões ao MINARS para verificar o andamento de seus pedidos de barrotes para a construção de sua casa, S. M. era sempre cumprimentado e tratado pelo nome, além de se engajar em conversações de cunho mais intimista e pessoal tanto com servidores do MINARS quanto com outras pessoas que para lá afluíam com pedidos de benefício similares aos seus. Ainda que dificuldades resultantes de sua discriminação, bem como de seus filhos, como "zairenses" estivessem presentes, seu status de refugiado, e portanto seus direitos de cidadão e sua situação legal não eram colocadas sob suspeita, sobre o que S. M. falava com orgulho, apontando como causa disso o fato de sua trajetória estar muito bem documentada, finalizando seus relatos com a expressão "j'ai de dossier"30.

Os refugiados residentes na Lunda Norte também possuíam dossiês de demandas e trajetos individuais. Ao adensar minhas incursões pelas comunidades de Nzagi e Candjamba, tomei conhecimento de histórias e projetos particulares de refugiados que posteriormente vi reproduzidas pelas narrativas de S. M. em Cabinda. Por exemplo, diversas pessoas manifestaram o desejo de serem reassentados no Canadá por possuírem lá parentes e amigos que poderiam apoiar sua inserção. Um dos líderes da comunidade do Nzagi relatou ter enviado cartas para embaixadas e organizações internacionais solicitando ajuda humanitária e denunciando as perseguições que sofria. Alegava, inclusive, que a chegada do apoio humanitário da WLF durante a guerra civil angolana teria sido resultado de uma das cartas que enviou.

Em Candjamba, um dos poucos refugiados que já possuía o cartão do COREDA relatou o desejo de montar uma empresa de importação e exportação como a que tinha na RDC antes de emigrar. Para tanto, necessitava de passaporte para realizar viagens internacionais como representante comercial. O SME, que é o órgão responsável pela emissão de passaportes angolanos, alegava ser necessário um documento do ACNUR declarando concordância com o procedimento, uma vez que a responsabilidade pela proteção de refugiados é compartilhada entre o Estado e a organização internacional. Assim, a perspectiva de obtenção do passaporte era, naquele momento, virtualmente nula, uma vez que as demandas pelo cartão do COREDA eram prioritárias e representavam um grande volume de processos.

Ademais, o atendimento a demandas individuais, ainda que fosse possível, ensejava acusações de favorecimento pelo JRS e ACNUR a determinadas pessoas e grupos dentro do conjunto de refugiados, colocando em evidência a formação de facções dentro das comunidades, algo indesejável do ponto de vista da política humanitária. Os dossiês individuais, neste contexto, eram, assim, menos

30 "Tenho dossiê", querendo dizer que possuía documentos que comprovam e justificam seu status jurídico de refugiado. 
eficazes do que a reprodução da expressão de temor, provocado agora não mais pela crise humanitária de seus lugares de origem, mas pela insegurança jurídica provocada pelo prolongamento da condição de provisoriedade conferida pelos documentos intermediários ao reconhecimento do status de refugiado, e que se traduzia em receio de abusos e conflitos em seus relacionamentos com instituições, autoridades e comunidades angolanas de seu entorno.

\section{Considerações finais}

Não obstante a concepção da RSD como um procedimento padrão, o modo como os sujeitos experienciam o processo de conversão de um imigrante em refugiado estabelece modelos concretos do que seja um refugiado tanto para o próprio solicitante quanto para as pessoas e instituições com as quais se relacionam no país anfitrião, engendrando diferentes estratégias de "situação" em relação a seus interlocutores. Como procurei demonstrar ao longo deste artigo, a narrativa de uma trajetória relativamente independente e associada a movimentos e personagens políticos específicos da história da RDC era apresentada por S. M. como principal argumento para seu reconhecimento como refugiado estatutário. A frase j'ai de dossier por ele utilizada significava, assim, não apenas o acúmulo de documentos que comprovavam sua condição, mas a expressão de uma trajetória individualizada que o distinguia de forma indubitável do restante dos solicitantes de asilo sobre os quais repousava sistematicamente a suspeita de se tratarem de "imigrantes econômicos". "Ter um dossier" permitia a S. M. se situar em suas relações pessoais e na forma como se apresentava às instituições, como um "exilado", e não como mais um "zairense", facilitando sua inclusão em programas de benefícios e auxílios governamentais destinados à população angolana de forma geral.

A análise comparativa das situações de refugiados em Cabinda e na Lunda Norte mostrou que a eficácia do agenciamento do dossiê individual reside menos em sua correspondência inata e autoevidente à definição de refugiado do que no contexto em que seu reconhecimento como refugiado foi produzido. Enquanto em Cabinda a noção de refugiado com a qual operavam os agentes estatais e as redes de relações pessoais de S. M. correspondia a um indivíduo e sua família com uma trajetória bem documentada de perseguições e tortura por grupos políticos bem definidos de seu país de origem, na Lunda Norte a noção de refugiado vinha sendo construída a partir do acúmulo de centenas de pessoas em duas aldeias específicas, o que tornava suas demandas cada vez mais numerosas e onerosas para as instituições responsáveis por seu atendimento. Na Lunda Norte, refugiados e solicitantes de asilo eram sistematicamente interpelados - e portanto "situados" - como "zairenses" cujas motivações para migrar se resumiam ao temor de perseguição imputado 
pelos mecanismos jurídicos de recepção das solicitações de asilo em massa que limitam os espaços de expressão de trajetórias e projetos particulares.

Para além da caracterização das "situações de refúgio" a partir de experiências de interlocução e/ou de interpelação de refugiados nos contextos de inserção ou, como buscam caracterizar as instituições responsáveis pela condução desta política, de "integração", a análise comparativa entre Lunda Norte e Cabinda levanta uma reflexão acerca dos desdobramentos que as noções socialmente construídas a respeito do que é um refugiado podem ter sobre a própria consecução dos programas de assistência. A identificação das "noções de refugiado" geradas pela interação dos sujeitos assim reconhecidos com as instituições e com comunidades de seu entorno parece, assim, ser relevante para a compreensão não somente dos casos onde a inserção/ integração é considerada bem sucedida, mas também dos casos em que os modelos exemplares - do "exilado" ou do "refugiado humanitário" - podem obstruir outras formas de reconhecimento de imigrantes como beneficiários de políticas públicas.

\section{Bibliografia}

AGAMBEN, Giorgio. Homo Sacer: o poder soberano e a vida nua. Belo Horizonte: UFMG, 2002.

AGIER, Michel. Le gouvernement humanitaire et la politique des réfugiés. Recueil Alexandrie: Référence, n. 10, 2006. Disponível em: < http://www.reseau-terra. eu/article569.html>. Acessado em: 15.12.2014.

ALBERT, Matthew. Prima facie determination of refugee legal status: an overview of its legal foundation. RSC Working Paper, n. 55, 2010, p. 7-66.

BAKEWELL, Oliver. Breaching the borders between research and practice: development NGOs and qualitative data. In SMITH, Matt (org.). Negotiating boundaries and borders: qualitative methodology and development research (Studies in qualitative methodology vol. 8). Oxford: Northumbria University, 2007, p. 217-238.

BARRETT, Michael. Social landscapes and moving people: the mysterious meaning of migration in western Zambia. New issues in refugee research, n. 78, 2003, p. $1-18$.

CLARK, John. The African stakes in the Congo war. London: Palgrave, 2005.

COLSON, Elizabeth. Forced Migration and the anthropological response. Journal of refugee studies, v. 16, n. 1, 2003, p. 1-18.

CRISP, Jeff. The local integration and local settlement of refugees: a conceptual and historical analysis. New issues in refugee research, n. 102, 2004, p. 1-8.

ELIAS, Norbert; SCOTSON, John. Os estabelecidos e os outsiders: sociologia das relações de poder a partir de uma pequena comunidade. Rio de Janeiro: Zahar, 2000.

FIELDEN, Alexandra. Local integration: an under-reported solution to protracted 
refugee situations. New issues in refugee research, n. 158, 2008, p. 1-21.

GLUCKMAN, Max. Análise de uma situação social na Zululândia moderna. In FELDMAN-BIANCO, Bela (org.). Antropologia das sociedades contemporâneas. São Paulo: UNESP, 2010, p. 237-364.

LÉVI-STRAUSS, Claude. O feiticeiro e sua magia. In Antropologia estrutural. São Paulo: Cosac \& Naify, 2012, p. 237-263.

MALKKI, Liisa. Purity and Exile: violence, memory, and national cosmology among Hutu refugees in Tanzania. Chicago: University of Chicago Press, 1995.

MALKKI, Liisa. Speechless emissaries: refugees, humanitarianism, and dehistoricization. Cultural Anthropology, v. 11, n. 3, 1996, p. 377-404.

MOORE, Henrietta. Fantasias de poder e fantasias de identidade: gênero, raça e violência. Cadernos Pagu, v. 14, 2000, p. 13-44.

MURISON, Jude. The politics of refugees and internally displaced persons in the Congo War. In CLARK, John F. The African stakes in the Congo war. London: Palgrave, 2005, p. 225-237.

RUTINWA, Bonaventure. Prima facie status and refugee protection. New issues in refugee research, n. 69, 2002, p. 1-27.

TALLIO, Virginie. La construction de la catégorie "réfugié" dans un camp en R.D.C.: rôle de l'institution, stratégies des exilés et place du chercheur. e-Migrinter, n. 9, 2012, p. 18-28.

UNHCR, United Nations High Commissioner for Refugees. Convention and protocol relating to the status of refugees (1951/1967). Basic documents, set. 2007. Disponível em: <www.unhcr.org/3b66c2aa10.html>. Acessado em: 15.12.2014.

VALLUY, Jérôme. Rejet des exilés: le grand retournement du droit de I'asile. Bellecombe-en-Bauges: Editions du Croquant, 2009.

ZETTER, Roger. More labels, fewer refugees: remaking the refugee label in an era of globalization. Journal of Refugee Studies, v. 20, n. 2, 2007, p. 172-192.

Recebido para publicação em 13.01.2016

Aceito para publicação em 17.03.2016

Received for publication in January 13 ${ }^{\text {th }}, 2016$

Accepted for publication in March 17 $7^{\text {th }}, 2016$

ISSN impresso: 1980-8585

ISSN eletrônico: 2237-9843

http://dx.doi.org/10.1590/1980-85852503880004711 